\title{
ErbB1 and ErbB3 co-over expression as a prognostic factor in gastric cancer
}

\author{
Meysam Moghbeli ${ }^{1}$, Yasha Makhdoumi², Mehrdad Soltani Delgosha ${ }^{3}$, Azadeh Aarabi $^{4}$, Ezzat Dadkhah ${ }^{3}$, \\ Bahram Memar ${ }^{5}$, Abbas Abdollahi ${ }^{6}$ and Mohammad Reza Abbaszadegan ${ }^{3,4^{*}}$
}

\begin{abstract}
Background: Epidermal growth factor receptor family members such as ErbB1 and ErbB3 are involved in tumor progression and metastasis. Although, there are various reports about the prognostic value of EGFR members separately in gastric cancer, there is not any report about the probable correlation between ErbB1 and ErbB3 co-expression and gastric cancer prognosis. In present study, we assessed the correlation between ErbB1 and ErbB3 co-overexpression (in the level of mRNA and protein expression) and gastric cancer prognosis for the first time.
\end{abstract}

Methods: ErbB1 and ErbB3 expressions were analyzed by immunohistochemistry and real-time PCR in 50 patients with gastric cancer. Parametric correlations were done between the ErbB1 and ErbB3 expression and clinicopathological features. Multivariate and logistic regression analyses were also done to assess the roles of ErbB1 and ErbB3 in tumor prognosis and survival.

Results: There were significant correlations between ErbB1/ErbB3 co-overexpression and tumor size $(p=0.026)$, macroscopic features $(p<0.05)$, tumor differentiation $(p<0.05)$, stage of tumor $(p<0.05)$, and recurrence $(p<0.05)$. Moreover, ErbB1/ErbB3 co-overexpression may predict the survival status of patients $(p<0.05)$.

Conclusion: ErbB1 and ErbB3 co-overexpression is accompanied with the poor prognosis and can be used efficiently in targeted therapy of gastric cancer patients.

Keywords: Gastric cancer, EGFR, HER3, Prognosis, Targeted therapy

\section{Background}

Gastric cancer is known as the fourth common cancer and the second leading cause of cancer-related deaths worldwide [1]. Most of the gastric cancer patients are diagnosed in advanced stages of tumor leading to a poor prognosis [2]. Tumor recurrence after the surgery is more common in tumors with advanced stages; therefore, adjuvant systemic chemotherapies have been developed to improve this problem [2]. It has been shown that the patients with advanced gastric cancer who can tolerate the side effects of chemotherapeutic treatments have real benefit in survival in comparison with the supportive care. However, the median survival time is not more

\footnotetext{
*Correspondence: abbaszadeganmr@mums.ac.ir

${ }^{3}$ Medical Genetics Research Center, Mashhad University of Medical Sciences, Mashhad, Iran

Full list of author information is available at the end of the article
}

than 13 months even in patients who were undergone the chemotherapeutic modalities [3]. The epidermal growth factor receptor (EGFR) family are the members of tyrosine kinase receptors that stimulate a number of signaling pathways and regulate diverse cellular processes such as proliferation, differentiation, survival, and migration $[4$, 5]. These signaling pathways are important in normal cellular homeostasis, therefore aberrant activation of the EGFR members can cause tumorigenesis. This protein family is comprised of four members including; ErbB1 (EGFR), ErbB2 (HER ${ }^{-}$/neu), ErbB3, and ErbB4 [6]. All of these four members share a common structure; these tyrosine kinases contain an extracellular ligand-binding domain with approximately 630 amino acids and a cytoplasmic tyrosine kinase domain [7-11]. Activation of these tyrosine kinases causes autophosphorylation on specific tyrosine residues and triggers a downstream signaling cascade via the phosphoinositide- 3 kinase 
(PI3K) and activated-Akt pathway. Therefore, ErbB family can be involved in malignant progression [12]. Except the ErbB2 that does not have a known ligand, the other members of ErbB family can be activated by specific ligands. Ligand-receptor interaction causes specific structural changes and receptor dimerization. It can be either homodimerization (ErbB2-ErbB2) or heterodimerization (ErbB1-ErbB4, ErbB2-HER3) [13]. Overexpression of ErbB receptors and their cognate ligands has been considered as one of the main causes of tumor progression [14, 15]. The ErbB1 and ErbB2 overexpression in gastric cancer is shown to be as the prognostic and efficient factors for the targeted therapy [2]. Gene amplification or EGFR overexpression have been observed in different solid tumors such as lung, colorectal, urinary bladder, breast, head and neck, esophageal, and gastric carcinomas [16-25]. ErbB3 overexpression was observed in a wide range of cancers including breast, ovary, lung, and prostate, as well as melanoma [26-30]. Although there is not any report of ErbB3 or ErbB4 overexpression in gastric cancer, ErbB3 expression is frequently seen in advanced stages of gastric cancers and is correlated with poor prognosis [31-33]. In human breast cancer, ErbB3 interacts with ErbB2 and thereby generates a potent oncogenic dimer that causes tumor progression [34]. Apart from various reports about the prognostic value of EGFR members separately in gastric cancer, there is not any report about the probable correlation between ErbB1 and ErbB3 co-expression and gastric cancer prognosis. Indeed, a panel of double EGFR markers may be more efficient in comparison with all of the regular single based markers in gastric cancer cases. In this study, ErbB1 and ErbB3 expressions in the levels of mRNA and protein were assessed for the first time in gastric cancer cases to evaluate the probable role of ErbB1 and ErbB3 co-expression in gastric cancer prognosis.

\section{Methods}

\section{Tissue samples}

Fresh tumor and adjacent normal tissues were obtained from 50 patients with gastric adenocarcinoma who were underwent a gastrectomy at Omid Hospital of Mashhad University of Medical Sciences. The patients did not receive any chemo-radio therapeutic treatment prior the surgery. Tissue samples were transferred to the RNA later solution immediately and stored in $-20{ }^{\circ} \mathrm{C}$ until RNA extraction. Inclusion criteria involved: no chemo-radio therapeutic treatment before the surgery and the tumor tissues were histologically examined by a pathologist to ensure that they contain at least $70 \%$ of tumor cells. Informed consent forms were obtained from the patients and protocol of study was approved by the research ethic committee.

\section{Immunohistochemistry}

The paraffin embedded tissues were stained with hematoxylin-eosin method to be checked for the presence of tumor cells. After deparaffinization and rehydration, all of the $2 \mathrm{~mm}$-thick sections were heated-pretreated with EDTA-TRIS solution $(\mathrm{PH}=7)$ in a microwave oven. After washing by TBS (Biogene, Australia), endogenous peroxide activity was inhibited by $\mathrm{H} 2 \mathrm{O} 2$ (3\%, Novocastra, USA). Protein block incubation was also performed to reduce the non-specific staining. The protocol followed by incubation of slides with ErbB1 and ErbB3 monoclonal antibodies (DAKO, Denmark). After $30 \mathrm{~min}$ of incubation with antibody, the slides were incubated by post primary block and then by Novolink polymer for 30 min (Novolink detection system REF RE7280-K). Finally, the slides were stained with DAB chromogen and hematoxylin.

\section{Immunohistochemical scoring system}

IHC staining was graded based on American Society of Clinical Oncology/College of American Pathology guideline $[35,36]$. This criterion included, $0=$ No membranous staining in tumor cells, $1+=$ Weak (staining in less than $10 \%$ of cells), $2+=$ intense complete staining (up to $30 \%$ of tumor cells), and $3+=$ Uniform intense staining (more than $30 \%$ of tumor cells). Scores of $2+/ 3+$ and $0 /+1$ were classified as over and normal expression, respectively.

\section{RNA extraction, CDNA Synthesis, and quantitative RT-PCR}

RNA extraction from the normal and tumor tissues was performed using RNeasy Mini kit (Qiagen, Germany). RevertAid first strand cDNA synthesis kit (Fermentas, Lithuania) was also used for the mRNA reverse transcription. Quantitative Real-time PCR was performed by specific primer sets (Table 1) in Stratagene Mx-3000P real-time thermocycler (Stratagene, La Jolla, CA) using the SYBR green PCR Master Mix (Fermentas, Lithuania). The following thermal profile was applied: 10 min at $95{ }^{\circ} \mathrm{C}$ and $\left(15 \mathrm{~s}\right.$ at $95{ }^{\circ} \mathrm{C}, 30 \mathrm{~s}$ at $57^{\circ} \mathrm{C}$, and $45 \mathrm{~s}$ at $\left.72{ }^{\circ} \mathrm{C}\right) 40$ cycles. Data were normalized by glyceraldehyde

Table 1 primer sequences for real time PCR

\begin{tabular}{lll}
\hline Primer sequence $\left(\mathbf{5}^{\prime}\right.$ to $\left.\mathbf{3}^{\prime}\right)$ & Amplified target & $\begin{array}{l}\text { Size } \\
\text { of amplicon } \\
\text { (bp) }\end{array}$ \\
\hline $\begin{array}{l}\text { GGAGAACTGCCAGAAACT } \\
\text { GACC }\end{array}$ & ErbB1-Exon junction 5-6 & 106 \\
GCCTGCAGCACACTGGTTG & ErbB1-Exon 6 & \\
CCCTGCCATGAGAACTGCAC & ErbB3-exon15 & 112 \\
$\begin{array}{l}\text { TCACTGTCAAAGCCATTGTCA } \\
\text { GAT }\end{array}$ & ErbB3-exon17 & \\
\hline
\end{tabular}


3-phosphate dehydrogenase (GAPDH) [37]. All experiments were performed in duplicates. A more than twofold fluorescence intensity of mRNA expression in tumor tissue in comparison with the corresponding normal tissues was considered as over expression. Less than twofold expression also was indicated as under expression, and the range between them was interpreted as normal expression.

\section{Prognostic assessment}

The patients were followed up 6 and 12 months after surgery by radio-oncologists. During each visit, all of patients were evaluated for recurrent disease and Karnofsky score (CA19-9) was measured through the physical examinations and diagnostic imaging. Thereafter, the prognosis was determined by oncologist based on clinical manifestation of patients.

\section{Statistical analysis}

The statistical analysis was done using SPSS 19.0 software (SPSS, Chicago, IL). $\mathrm{X}^{2}$ test and Fisher exact test were used for possible association between the levels of each proteins expression and clinicopathological features. Kaplan-Meier curves were generated for overall survival and statistical significance was determined using the logrank test. Correlation between ErbB1 and ErbB3 levels of gene expression was evaluated by Pearson's correlation. The multivariate proportional Cox models were applied to assess the prognostic significance of HER expressions, Lauren classification, lymph node involvement, tumor invasion, and differentiation. Logistic regression model was used to assess if the ErbB1 and ErbB3 can be used as independent prediction factors of prognosis. All the statistical tests were defined significantly as a $\mathrm{p}<0.05$.

\section{Results}

\section{Clinicopathological features of patients}

Fifty gastric cancer patients comprising 38 (76\%) male and $12(24 \%)$ females were enrolled in the present study. Age of patients was ranged between 40 and 80 years old with mean age of $69 \pm 9.3$ years old. Tumor sizes were also between 3 and $10 \mathrm{~cm}$ with mean size of $8.2 \pm 1.7 \mathrm{~cm}$. Majority of tumors were located in non-cardia $(38 / 50$, $76 \%)$, positive lymph node metastasis $(48 / 50,96 \%)$, differentiated $(30 / 50,60 \%)$, in tumor stages of I/II $(28 / 50$, $56 \%$ ), and with T3/4 depth of invasion (47/50, 94\%). Moreover, twenty-one out of 50 (42\%) patients had tumor relapse. All the clinicopathological features of patients are mentioned in Table 2.

\section{EGFR family expression and prognosis}

ErbB1 and ErbB3 over expression were observed in 23 (46\%) and 20 (40\%) of patients, respectively. Fourteen out of $50(28 \%)$ had ErbB1/3 over expression. ErbB1 protein expression was observed in different parts of tumor cells including; membranous $(14 / 50,28 \%)$, cytoplasm $(28 / 50$, $56 \%)$, and 8 out of $50(16 \%)$ cases had membranous and cytoplasmic expression simultaneously. However, ErbB3 protein expression was observed in cytoplasm (Fig. 1). Seventeen, 19, 20, and 20 out of 20 ErbB3 over expressed cases were infiltrative, poorly differentiated, stage of III/ $\mathrm{IV}$, and with a positive tumor relapse $(\mathrm{p}<0.05)$, respectively. ErbB1 protein expression was also significantly correlated with macroscopic features $(\mathrm{p}=0.028)$, tumor differentiation $(\mathrm{p}=0.028)$, recurrence $(\mathrm{p}=0.013)$, and stage of tumor $(\mathrm{p}=0.027)$. There was a significant correlation between ErbB1/3 over expression and grade of tumor in which 13 out of 14 cases $(92.9 \%)$ were poorly differentiated $(\mathrm{p}<0.05)$. There was a significant correlation between ErbB1/3 over expression and tumor relapse in which all of the cases with such over expression had tumor relapse $(\mathrm{p}<0.05)$. Moreover, there was a significant correlation between ErbB1/3 over expression and stage of tumor in which all of them were in tumor stages of III/IV $(\mathrm{p}<0.05)$. Twelve out of the 14 ErbB1/3 over expressed cases were infiltrative type $(\mathrm{p}<0.05)$. Although, there wasn't any significant correlation between tumor depth of invasion and ErbB1/3 expression, all of the ErbB1/3 over expressed cases had T3/4 depth of invasion. There was also a significant correlation between tumor size and ErbB3/1 over expression in the level of protein in which the over expressed tumors were smaller than tumors with normal expression $(4.25 \pm 0.854$ vs. $5.14 \pm 0.382 \mathrm{~cm})$. In the case of age, it was shown that the ErbB1/3 over expressed cases were older than the other cases ( $73 \pm 6.0$ vs. $63 \pm 1.8$ years old). ErbB3 mRNA over expression was significantly correlated with tumor differentiation $(\mathrm{p}<0.05)$, lymph node involvement $(\mathrm{p}=0.001)$, stage of tumor $(\mathrm{p}<0.05)$, and recurrence $(\mathrm{p}<0.05)$. ErbB1 mRNA over expression was also significantly correlated with ErbB3 protein expression $(\mathrm{p}=0.045)$, tumor differentiation $(p=0.048)$, and recurrence $(p=0.026)$. Regarding the log rank test, there wasn't any significant correlation between ErbB1 protein expression and survival rate $(p=0.267)$. Whereas, ErbB3 protein expression was significantly associated with poor survival of the patients $(\mathrm{p}=0.002)$. Moreover, the patients who had over expression in both of these markers had a poor survival $(\mathrm{p}=0.006)$ (Fig. 2). The prognostic relevance of ErbB1/3 was evaluated using a multivariate proportional hazard model adjusted for the established clinicopathological features such as histological type, node involvement, tumor location, and differentiation. ErbB3 protein expression $(\mathrm{p}=0.046), \mathrm{ErbB} 1 / 3$ over expression $(\mathrm{p}=0.05)$, histological type $(\mathrm{p}=0.018)$, and lymph node involvement $(p=0.049)$ were considered as prognostic 


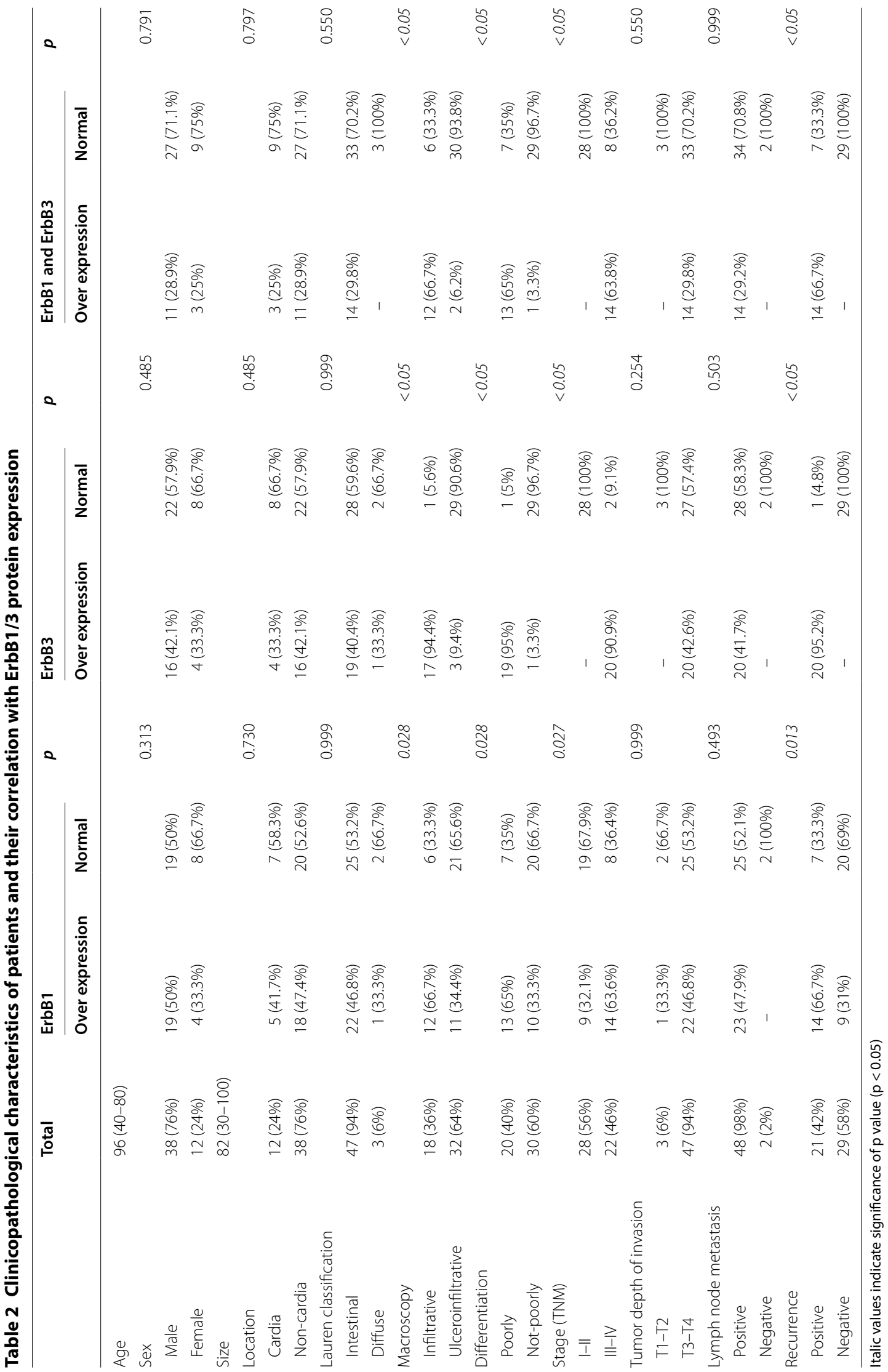




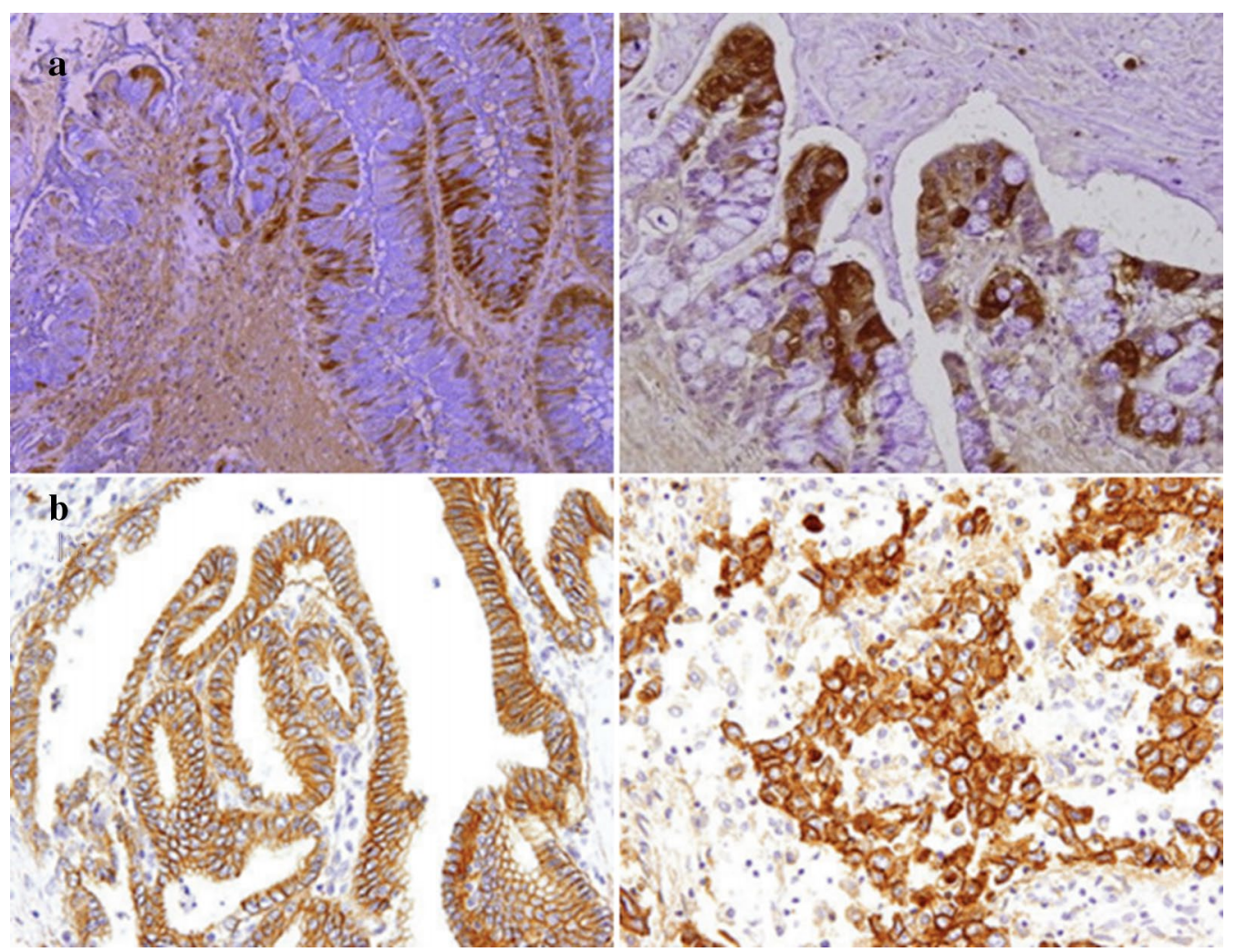

Fig. 1 Immunohistochemical staining of ErbB3 in gastric cancer species (a). EGFR immunohistochemical staining (b)

factors (Table 3). The logistic regression model also showed that the ErbB1/ErbB3 over expression, lymph node involvement, and size of tumor were independent prognostic factors (Table 4).

\section{Discussion}

Prognostic role of EGFR family is reported in several cancers such as lung, colorectal, and ovarian cancer [17, 30, 38]. Although, the correlation between EGFR overexpression and poor prognosis was observed in many studies, EGFR structural alterations are rare in gastric cancer [39]. It has been shown that, over expression of ErbB1 and ErbB3, and ErbB4 proteins were significantly associated with poor prognosis in gastric cancer patients [2]. EGFR expression has been correlated with shorter overall survival, advanced stages of tumor, and lymph node metastasis in gastric cancer $[40,41]$. However, there are some reports about the positive role of EGFR expression in gastric cancer patients and improving the survival of such patients [42]. EGFR has a wide range of expression in gastric cancer ranging from 2 to 44\% [41, 43, 44]. Although, HER overexpression has been reported in gastric cancer patients, there is a conflict about the correlation between HER positivity and patient survival $[45,46]$.
In the present study we assessed the probable correlation between concomitant EGFR and ErbB3 expression and prognosis in gastric cancer. There was a direct correlation between EGFR and ErbB3 expression highlighting that these heterodimers have a significant prognostic role in gastric cancer. It was shown that there were also significant correlations between EGFR/ErbB3 expression and clinicopathological features of patients. However, there was not any correlation between ErbB1 over expression and poor prognosis which is in contrast with some other reports in gastric cancer [40]. We showed that EGFR and ErbB3 co-overexpression is an independent prognostic factor and can also predict the poor survival rate. Although, level of ErbB3 protein expression was correlated with prognosis according to Log-Rank test, there was not any significant correlation between the ErbB1 protein expression and prognosis. In recent studies, it was observed that anti-ErbB2 targeted therapy can cause compensatory overexpression of ErbB3 in breast and colorectal cancers [47, 48]. ErbB2 and ErbB3 cooverexpression decreases survival rate of breast cancer patients $[49,50]$. We have observed that there was a significant correlation between ErbB1 and ErbB3 and ErbB3 protein co-overexpression with CA19-9 serum marker. It 


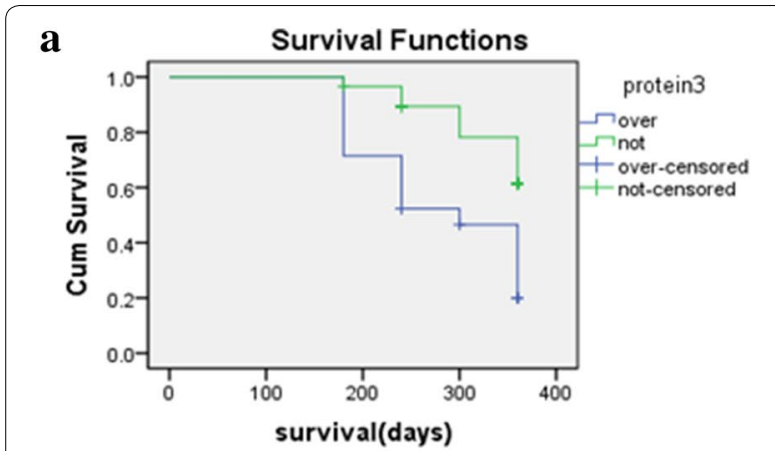

b

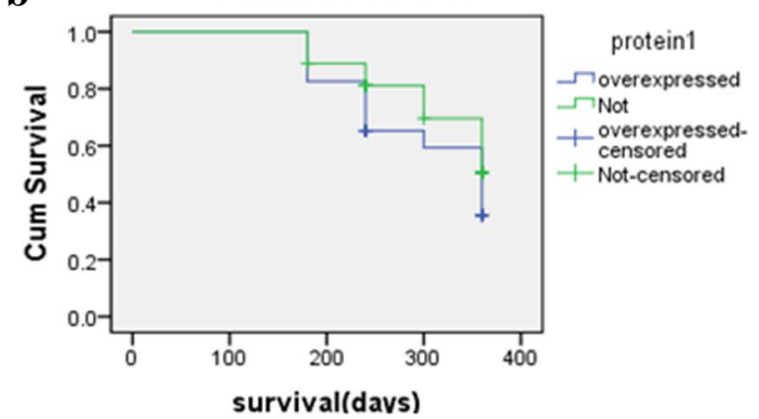

c

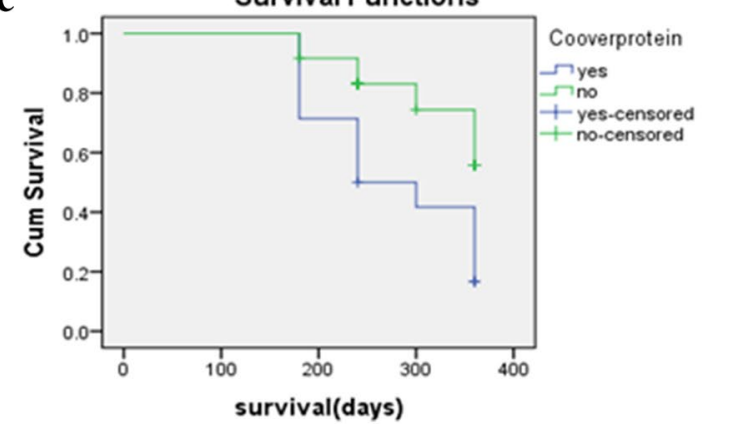

Fig. 2 Kaplan-Meier curves for the overall survival of patients with ErbB3 expression (a). ErbB1 expression (b), ErbB1 and ErbB3 co-overexpression (c)

Table 3 Prognostic factors in a multivariate proportional hazard model of the Cox regression

\begin{tabular}{lll}
\hline Factors & HR $(\mathbf{9 5} \% \mathbf{C l})$ & p value \\
\hline Protein ErbB1 & $9.15(0.553-33.35)$ & 0.083 \\
Protein ErbB3 & $0.11(0.013-0.96)$ & 0.046 \\
Intestinal/diffuse & $5.47(1.34-22.34)$ & 0.018 \\
Node involvement & $1.18(1.00-1.40)$ & 0.049 \\
Tissue differentiation & $4.30(0.553-33.50)$ & 0.163 \\
mRNA ErbB1 & $1.12(0.848-1.50)$ & 0.407 \\
mRNA ErbB3 & $0.90(0.688-1.15)$ & 0.476 \\
Tumor location & $0.54(0.201-1.48)$ & 0.237 \\
Co-overexpression ErbB1 and & $0.09(0.008-1.02)$ & 0.050 \\
ErbB3 & & \\
\hline
\end{tabular}

Italic values indicate significance of $p$ value $(p<0.05)$
Table 4 Independent Prognostic factors according to Logistic regression model

\begin{tabular}{ll}
\hline Factors & p value \\
\hline ErbB1 mRNA & 0.061 \\
ErbB3 mRNA & 0.461 \\
ErbB1 protein & 0.469 \\
ErbB3 protein & 0.597 \\
Sex & 0.298 \\
Size & 0.050 \\
Age & 0.163 \\
Lymph node involvement & 0.011 \\
Tumor tissue differentiation & 0.318 \\
Stage & 0.228 \\
Co overexpression ErbB1 and ErbB3 & 0.029 \\
Tumor location & 0.759 \\
\hline
\end{tabular}

Italic values indicate significance of $p$ value $(p<0.05)$

was observed that co-over expression of these markers have a correlation with higher ages of patients. Moreover, co-over expression was also associated with tumor size in which the over expressed cases had bigger tumors in comparison with the other cases. This refers to the role of ErbB1/3 in early steps of gastric tumors and probably it has not an important role in advanced steps during the gastric cancer progression. Regarding this fact that the ErbB1/3 over expressed cases are in stages of II/IV and have T3/4 depth of invasion, therefore these markers cannot be used as diagnostic markers for the early detection of gastric cancers. Since, all of the ErbB1/3 over expressed cases had metastatic lymph nodes; it seems that these markers can be used for the detection of aggressive type of gastric cancer.

\section{Conclusion}

Co-overexpression of ErbB1 and ErbB3 is accompanied with poor prognosis and can be the cause of resistance to anti-ErbB1/3 therapy. Therefore, targeted therapy inhibits the interaction between ErbB1 and ErbB3 and can be more effective in eradication of tumor progression. Besides, ErbB1 and ErbB3 inhibitors can also prevent the ErbB3 overexpression. Moreover, it seems that the combination of ErbB1/3 can be used as a diagnostic method for the invasive gastric cancer tumors.

\section{Abbreviations}

EGFR: epidermal growth factor receptor; GAPDH: glyceraldehyde 3-phosphate dehydrogenase.

\section{Authors' contributions}

$M M, Y M, M S D, A A$, and ED were involved in experiments and drafting. BM and AA were involved in pathology and surgery. MRA supervised the project. All authors read and approved the final manuscript. 


\section{Author details}

${ }^{1}$ Department of Modern Sciences and Technologies, Faculty of Medicine, Mashhad University of Medical Sciences, Mashhad, Iran. ${ }^{2}$ Cancer Research Center, Mashhad University of Medical Sciences, Mashhad, Iran. ${ }^{3}$ Medical Genetics Research Center, Mashhad University of Medical Sciences, Mashhad, Iran. ${ }^{4}$ Immunology Research Center, Mashhad University of Medical Sciences, Mashhad, Iran. ${ }^{5}$ Surgical oncology research center, Mashhad University of Medical Sciences, Mashhad, Iran. ${ }^{6}$ Surgical oncology research center, Mashhad University of Medical Sciences, Mashhad, Iran.

\section{Acknowledgements}

Not applicable.

\section{Competing interests}

The authors declare that they have no competing interests.

\section{Availability of data and materials}

The datasets used and/or analyzed during the current study are available from the corresponding author on reasonable request.

\section{Consent for publication}

Not applicable.

\section{Ethics approval and consent to participate}

The study was approved by the Ethics Committee of Mashhad University of Medical Sciences [900496]. All participants gave written informed consent to participate.

\section{Funding}

None.

\section{Publisher's Note}

Springer Nature remains neutral with regard to jurisdictional claims in published maps and institutional affiliations.

\section{Received: 6 June 2018 Accepted: 14 December 2018}

Published online: 08 January 2019

\section{References}

1. Orditura M, et al. Treatment of gastric cancer. World J Gastroenterol. 2014;20(7):1635-49.

2. Hayashi $\mathrm{M}$, et al. High expression of HER3 is associated with a decreased survival in gastric cancer. Clin Cancer Res. 2008;14(23):7843-9.

3. Koizumi W, et al. S-1 plus cisplatin versus S-1 alone for first-line treatment of advanced gastric cancer (SPIRITS trial): a phase III trial. Lancet Oncol. 2008;9(3):215-21.

4. Schlessinger J, Lemmon MA. Nuclear signaling by receptor tyrosine kinases: the first robin of spring. Cell. 2006;127(1):45-8.

5. Moghbeli $M$, et al. Association of PYGO2 and EGFR in esophageal squamous cell carcinoma. Med Oncol. 2013;30(2):516.

6. Zwick E, Bange J, Ullrich A. Receptor tyrosine kinases as targets for anticancer drugs. Trends Mol Med. 2002;8(1):17-23.

7. Buzdar AU, et al. Significantly higher pathologic complete remission rate after neoadjuvant therapy with trastuzumab, paclitaxel, and epirubicin chemotherapy: results of a randomized trial in human epiderma growth factor receptor 2-positive operable breast cancer. J Clin Oncol. 2005;23(16):3676-85.

8. Carpenter G. Receptors for epidermal growth factor and other polypeptide mitogens. Annu Rev Biochem. 1987;56:881-914.

9. Cho HS, et al. Structure of the extracellular region of HER2 alone and in complex with the Herceptin Fab. Nature. 2003;421(6924):756-60.

10. Joensuu $\mathrm{H}$, et al. Fluorouracil, epirubicin, and cyclophosphamide with either docetaxel or vinorelbine, with or without trastuzumab, as adjuvant treatments of breast cancer: final results of the FinHer Trial. J Clin Oncol. 2009;27(34):5685-92.

11. Piccart-Gebhart MJ, et al. Trastuzumab after adjuvant chemotherapy in HER2-positive breast cancer. N Engl J Med. 2005;353(16):1659-72.
12. Yarden Y, Sliwkowski MX. Untangling the ErbB signalling network. Nat Rev Mol Cell Biol. 2001;2(2):127-37.

13. Yarden $Y$. The EGFR family and its ligands in human cancer signalling mechanisms and therapeutic opportunities. Eur J Cancer. 2001;37(Suppl 4):S3-8.

14. Hynes NE, Lane HA. ERBB receptors and cancer: the complexity of targeted inhibitors. Nat Rev Cancer. 2005;5(5):341-54.

15. Massie C, Mills IG. The developing role of receptors and adaptors. Nat Rev Cancer. 2006:6(5):403-9.

16. Cappuzzo F, et al. Epidermal growth factor receptor gene and protein and gefitinib sensitivity in non-small-cell lung cancer. J Natl Cancer Inst. 2005;97(9):643-55.

17. Hirsch FR, et al. Epidermal growth factor receptor in non-small-cell lung carcinomas: correlation between gene copy number and protein expression and impact on prognosis. J Clin Oncol. 2003;21(20):3798-807.

18. Ishitoya J, et al. Gene amplification and overexpression of EGF receptor in squamous cell carcinomas of the head and neck. Br J Cancer. 1989:59(4):559-62.

19. Kimura M, et al. A proposal for diagnostically meaningful criteria to classify increased epidermal growth factor receptor and c-erbB-2 gene copy numbers in gastric carcinoma, based on correlation of fluorescence in situ hybridization and immunohistochemical measurements. Virchows Arch. 2004;445(3):255-62

20. Kimura M, et al. Usefulness and limitation of multiple endoscopic biopsy sampling for epidermal growth factor receptor and c-erbB-2 testing in patients with gastric adenocarcinoma. Jpn J Clin Oncol. 2005:35(6):324-31.

21. Lemoine NR, et al. Amplification and overexpression of the EGF receptor and c-erbB-2 proto-oncogenes in human stomach cancer. Br J Cancer. 1991;64(1):79-83.

22. Perez EA. The role of adjuvant monoclonal antibody therapy for breast cancer: rationale and new studies. Curr Oncol Rep. 2001;3(6):516-22.

23. Shia J, et al. Epidermal growth factor receptor expression and gene amplification in colorectal carcinoma: an immunohistochemical and chromogenic in situ hybridization study. Mod Pathol. 2005;18(10):1350-6.

24. Wang KL, et al. Expression of epidermal growth factor receptor in esophageal and esophagogastric junction adenocarcinomas: association with poor outcome. Cancer. 2007;109(4):658-67.

25. Wang $X$, et al. Epidermal growth factor receptor protein expression and gene amplification in small cell carcinoma of the urinary bladder. Clin Cancer Res. 2007;13(3):953-7.

26. Reschke $M$, et al. HER3 is a determinant for poor prognosis in melanoma. Clin Cancer Res. 2008;14(16):5188-97.

27. Sanidas EE, et al. Expression of the c-erbB-3 gene product in gastric cancer. Int J Cancer. 1993;54(6):935-40.

28. Sithanandam $\mathrm{G}$, et al. Inactivation of ErbB3 by siRNA promotes apoptosis and attenuates growth and invasiveness of human lung adenocarcinoma cell line A549. Oncogene. 2005;24(11):1847-59.

29. Soler $M$, et al. HER3 is required for the maintenance of neuregulindependent and -independent attributes of malignant progression in prostate cancer cells. Int J Cancer. 2009;125(11):2565-75.

30. Tanner B, et al. ErbB-3 predicts survival in ovarian cancer. J Clin Oncol. 2006:24(26):4317-23

31. Slesak $B$, et al. Expression of epidermal growth factor receptor family proteins (EGFR, c-erbB-2 and c-erbB-3) in gastric cancer and chronic gastritis. Anticancer Res. 1998;18(4A):2727-32.

32. Witton CJ, et al. Expression of the HER1-4 family of receptor tyrosine kinases in breast cancer. J Pathol. 2003;200(3):290-7.

33. Yi ES, et al. High c-erbB-3 protein expression is associated with shorter survival in advanced non-small cell lung carcinomas. Mod Pathol. 1997; 10(2):142-8

34. Wallasch $\mathrm{C}$, et al. Heregulin-dependent regulation of HER2/neu oncogenic signaling by heterodimerization with HER3. EMBO J. 1995:14(17):4267-75.

35. Ambrosio MR, et al. Carbonic anhydrase IX is a marker of hypoxia and correlates with higher Gleason scores and ISUP grading in prostate cancer. Diagn Pathol. 2016;11(1):45.

36. Vergara-Lluri ME, et al. High concordance between HercepTest immunohistochemistry and ERBB2 fluorescence in situ hybridization before and after implementation of American Society of Clinical 
Oncology/College of American Pathology 2007 guidelines. Mod Pathol. 2012;25(10):1326-32.

37. Moghbeli M, et al. Role of hMLH1 and E-cadherin promoter methylation in gastric cancer progression. J Gastrointest Cancer. 2014;45(1):40-7.

38. Mayer A, et al. The prognostic significance of proliferating cell nuclear antigen, epidermal growth factor receptor, and mdr gene expression in colorectal cancer. Cancer. 1993;71(8):2454-60.

39. Moutinho C, et al. Epidermal growth factor receptor structural alterations in gastric cancer. BMC Cancer. 2008;8:10

40. Kim MA, et al. EGFR in gastric carcinomas: prognostic significance of protein overexpression and high gene copy number. Histopathology. 2008;52(6):738-46.

41. Lieto $E$, et al. Expression of vascular endothelial growth factor (VEGF) and epidermal growth factor receptor (EGFR) is an independent prognostic indicator of worse outcome in gastric cancer patients. Ann Surg Oncol. 2008;15(1):69-79.

42. Kim JS, et al. Biomarker analysis in stage III-IV (MO) gastric cancer patients who received curative surgery followed by adjuvant 5-fluorouracil and cisplatin chemotherapy: epidermal growth factor receptor (EGFR) associated with favourable survival. Br J Cancer. 2009;100(5):732-8.

43. Galizia G, et al. Epidermal growth factor receptor (EGFR) expression is associated with a worse prognosis in gastric cancer patients undergoing curative surgery. World J Surg. 2007;31(7):1458-68.
44. Mammano E, et al. Epidermal growth factor receptor (EGFR): mutational and protein expression analysis in gastric cancer. Anticancer Res. 2006;26(5A):3547-50.

45. Elebro J, et al. Expression and Prognostic Significance of Human Epidermal Growth Factor Receptors 1, 2 and 3 in Periampullary Adenocarcinoma. PLoS ONE. 2016;11(4):e0153533.

46. Terashima $\mathrm{M}$, et al. Impact of expression of human epidermal growth factor receptors EGFR and ERBB2 on survival in stage II/III gastric cancer. Clin Cancer Res. 2012:18(21):5992-6000.

47. Sergina NV, et al. Escape from HER-family tyrosine kinase inhibitor therapy by the kinase-inactive HER3. Nature. 2007;445(7126):437-41.

48. Maurer CA, et al. Increased expression of erbB3 in colorectal cancer is associated with concomitant increase in the level of erbB2. Hum Pathol. 1998;29(8):771-7.

49. Abd El-Rehim DM, et al. Expression and co-expression of the members of the epidermal growth factor receptor (EGFR) family in invasive breast carcinoma. Br J Cancer. 2004;91 (8):1532-42.

50. Suo Z, et al. EGFR family expression in breast carcinomas c-erbB-2 and c-erbB-4 receptors have different effects on survival. J Pathol. 2002;196(1):17-25
Ready to submit your research? Choose BMC and benefit from:

- fast, convenient online submission

- thorough peer review by experienced researchers in your field

- rapid publication on acceptance

- support for research data, including large and complex data types

- gold Open Access which fosters wider collaboration and increased citations

- maximum visibility for your research: over 100M website views per year

At BMC, research is always in progress.

Learn more biomedcentral.com/submissions 